\title{
The Common Clinical Presentation of Patients Selected for Septoplasty in Northern Saudi Arabia
}

\author{
Abdullah D. Alotaibi $\mathbb{D}^{1},{ }^{1}$ Bassam Ahmed Almutlaq $\mathbb{D}^{2},{ }^{2}$ Fahad Nashmi Alshammari, \\ and Hussain Gadelkarim Ahmed ${ }^{2}$ \\ ${ }^{1}$ University of Hail, College of Medicine, Department of Otolaryngology Head and Neck Surgery, Hail, Saudi Arabia \\ ${ }^{2}$ University of Hail, College of Medicine, Hail, Saudi Arabia \\ ${ }^{3}$ King Khalid Hospital, Department of Otolaryngology Head and Neck Surgery, Hail, Saudi Arabia
}

Correspondence should be addressed to Abdullah D. Alotaibi; adqo@yahoo.com

Received 16 December 2017; Revised 18 April 2018; Accepted 7 May 2018; Published 3 June 2018

Academic Editor: Stefano Di Girolamo

Copyright ( 2018 Abdullah D. Alotaibi et al. This is an open access article distributed under the Creative Commons Attribution License, which permits unrestricted use, distribution, and reproduction in any medium, provided the original work is properly cited.

\begin{abstract}
Background. Nasal septal deviation (NSD) plays a critical role in nasal obstruction symptoms, aesthetic look of the nose, increased nasal resistance, and occasionally snoring. Septoplasty is the most common method for correction of deviated nasal septum (DNS). Therefore, the aim of the present study was to assess the association between initial clinical presentations of patients selected for septoplasty and demographical characteristics in Northern Saudi Arabia. Methodology. Archives related to all patients selected for septoplasty between 2012 and 2017 were retrieved from ENT Department at King Khalid Hospital in Hail, Northern Saudi Arabia. Only adults over 18 years of age were included in this study. Results. With regard to the clinical presentations, almost all patients presented with variable degrees of nasal congestions, nasal blockages, breathing troubles, sleeping troubles, and exercise problems. Conclusion. Nasal obstruction is prevalent in Northern Saudi Arabia with peaks being in the years 2016 and 2014 with the most etiological factor being DNS.
\end{abstract}

\section{Introduction}

Surgical and medical management of nasal obstruction is the common measure in otolaryngologist practice. The perfect management of deviated nasal septum (DNS) is septoplasty [1]. Chronic nasal airway obstruction is one of the most frequent complaints that patients complain of to otolaryngologists. DNS is a common anatomic disparity and the most common cause of nasal obstruction [2-4]. Surgical amendment of the DNS is the most frequent ear, nose, and throat (ENT) operation in adults [5].

Septoplasty is a surgical procedure that is done to correct a DNS. A DNS arises when the cartilage that separates the nostrils is out of place. This can cause various breathing difficulties. Septoplasty is one of the most frequently performed otorhinolaryngological procedures, which might be very challenging for many surgeons. A precise preoperative diagnosis of pathologies of the septum in the situation of the nasal cavity is crucial for the success of surgery.
Intraoperative visualization through microscope or endoscope is very supportive for the surgeon and for the training of the residents. The new method of septoplasty with the phases of methodology, mobilization, resection/repositioning, and reconstruction/fixation is offered. As particularly pathologies of the caudal septum are responsible for failures of septal surgery, some special difficulties of this region such as the vertical fracture of the caudal septum, the deficiency of caudal septum, or anterior convexities of the cartilaginous septum are debated $[6,7]$.

Annual septoplasty rates, however, vary between countries. More than 20,000 septoplasties, (3.8 septoplasties per 10,000 inhabitants) were done in England between 2012 and 2013 [8]. In spite of the significant number of septoplasties achieved each year, complications after this process are relatively rare. Most complications result from insufficient surgical preparation or poor performance and often can be avoided. Surgeons should discuss these risks with patients before surgery as part of the informed consent process [9]. 
Patients selected for septoplasty present with diverse clinical presentations, particularly those with DNS. The occurrence of these clinical presentations may differ in association with demographical features of patients in specific population. Therefore, the aim of the present study was to assess the association between initial clinical presentations of patients selected for septoplasty and demographical characteristics in Northern Saudi Arabia.

\section{Materials and Methods}

This study involved 131 patients that presented with nasal obstruction and that were subsequently selected for septoplasty. Archives related to all selected patients for septoplasty between 2012 and 2017 were retrieved from ENT Department at King Khalid Hospital in Hail, Northern Saudi Arabia. Only adults over 18 years of age were included in this study. Patients' medical records were investigated, and patients with a history of rhinoplasty, cranial and facial trauma, or bone deformity (except DNS) and patients with mass in the nasal cavity were excluded from the study. Several nasal obstruction related clinical presentations were recorded, including nasal congestion, nasal blockages, breathing troubles, sleeping troubles, and exercise problems. Demographical characteristics including age, gender, and residence were also recorded.

Patients were assigned to septoplasty (with or without concurrent turbinate surgery) and the procedure was performed within 3 to 5 weeks after final surgical treatment choice.

\section{Ethical Consent}

Our study protocol conformed with the 2013 Declaration of Helsinki and this study was approved by the ethics committee of the College of Medicine, University of Hail, Saudi Arabia.

\section{Statistical Analysis}

Statistical analysis was performed using SPSS software for Windows (version 16.0, SPSS Inc., Chicago, IL, USA). Categorical variables are given as frequencies and percentages, as well as continuous variables. For all statistical comparisons, a $p$ value below 0.05 was considered statistically significant.

\section{Results}

The present study investigated retrospectively 131 consecutive cases of nasal blockages related abnormalities, their ages ranging from 18 to 42 years, with a mean age of 26 years. Most of the patients were 21-25 years old, followed by age ranges $36-30,<20$ years, and 31-35 years, representing 43,28 , 27 , and 19, respectively, as indicated in Table 1 and Figure 1. The majority of males were found at age group 21-25 years followed by 26-30 and 31-35 years constituting 29, 26, and 17 , respectively. The majority of females were found at age group 21-25 years, followed by $<20$ years constituting 14 and

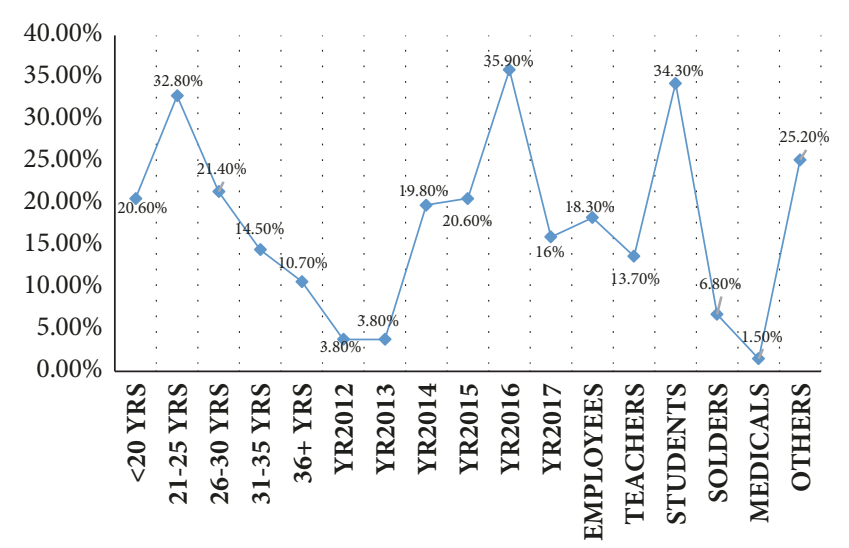

Figure 1: Description of the study population by age, year of admission, and occupations.

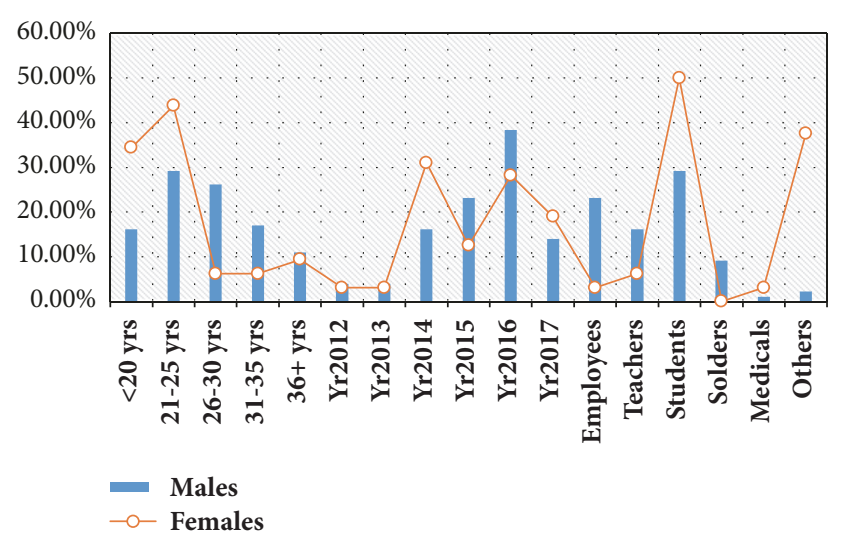

FIGURE 2: Description of the study population by gender and demographical characteristics.

11 correspondingly, as indicated in Table 1 and Figures 1 and 2.

Out of 131 patients, 99/131 (75.6\%) were males and 32/131 $(24.4 \%)$ were females, giving male-to-female ratio of 3.09 to 1.00 . The majority of the patients were registered in the year 2016 followed by years 2015, 2014, 2017, 2012, and 2013, representing 47 (35.9\%), 27 (20.6\%), 26 (19.8\%), 21 $(16.1 \%)$, and $5(3.8 \%)$, respectively. For males, most of them presented in the year 2016 followed by years 2015, 2014, 2017, 2013, and 2012, constituting 38/99 (38.4\%), 23/99 (23.2\%), $16 / 99$ (16.2\%), 14/99 (14\%), and 4/99 (4.1\%), respectively. For females, most of them presented in the year 2014 followed by years 2016 and 2017, representing 10/32 (31\%), 9/32 (28.2\%), and $7 / 32(19 \%)$, in this order, as shown in Table 1 and Figures 1 and 2 .

With regard to the occupations, the majority of the patients were students representing 45/131 (34.4\%) followed by others, employees, teachers, and soldiers, constituting 33 (25.2\%), $24(18.3 \%), 18(13.7 \%)$, and $9(6.8 \%)$, in this order. For males, the great majority were students followed by employees and others representing 29/99 (29.3\%), 23 (23.2\%), and $21(21.2 \%)$, correspondingly. For females, the majority were students followed by others, constituting 16/32 (50\%) 
TABLE 1: Study subjects by demographical characteristics.

\begin{tabular}{|c|c|c|c|c|}
\hline Variable & Category & Males & Females & Total \\
\hline \multicolumn{5}{|c|}{ Year of Diagnosis } \\
\hline & 2012 & 4 & 1 & 5 \\
\hline & 2013 & 4 & 1 & 5 \\
\hline & 2014 & 16 & 10 & 26 \\
\hline & 2015 & 23 & 4 & 27 \\
\hline & 2016 & 38 & 9 & 47 \\
\hline & 2017 & 14 & 7 & 21 \\
\hline & Total & 99 & 32 & 131 \\
\hline \multicolumn{5}{|c|}{ Age groups } \\
\hline & $<20$ years & 16 & 11 & 27 \\
\hline & $21-25$ & 29 & 14 & 43 \\
\hline & $26-30$ & 26 & 2 & 28 \\
\hline & $31-35$ & 17 & 2 & 19 \\
\hline & $36+$ & 11 & 3 & 14 \\
\hline \multicolumn{5}{|c|}{ Occupations } \\
\hline & Employees & 23 & 1 & 24 \\
\hline & Teachers & 16 & 2 & 18 \\
\hline & Students & 29 & 16 & 45 \\
\hline & Solders & 9 & 0 & 9 \\
\hline & Medicals & 1 & 1 & 2 \\
\hline & others & 21 & 12 & 33 \\
\hline
\end{tabular}

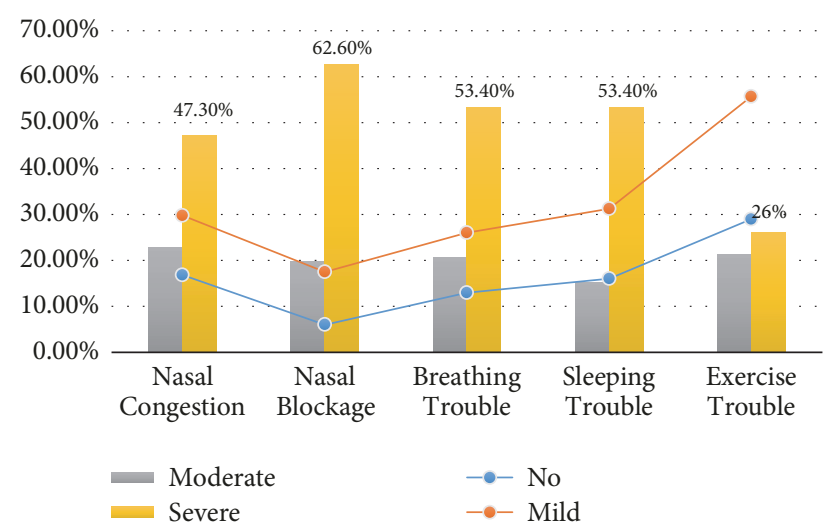

FIGURE 3: Description of patients by initial clinical presentation.

and $12(37.5 \%)$, respectively, as indicated in Table 1 and Figures 1 and 2.

With regard to the clinical presentations, almost all patients presented with variable degrees of nasal congestions, nasal blockages, breathing troubles, sleeping troubles, and exercise problems. For nasal congestions, 17 (13\%), 30 $(22.9 \%)$, and $62(47.3 \%)$ of the patients presented with mild, moderate, and severe nasal congestions, respectively. For nasal blockages, 15 (11.5\%), 26 (19.8\%), and $82(62.6 \%)$ of the patients presented with mild, moderate, and severe nasal blockages. For breathing troubles, 17 (13\%), 27 (20.6\%), and $70(53.4 \%)$ of the patients presented with mild, moderate, and severe breathing trouble. For sleeping troubles, 20 (15.3\%), $20(15.3 \%)$, and $70(53.4 \%)$ of the patients presented with mild, moderate, and severe sleeping troubles. For exercise troubles, $31(26.7 \%), 28(21.3 \%)$, and $34(26 \%)$ of the patients presented with mild, moderate, and severe exercise troubles, as indicated in Table 2 and Figure 3.

Table 3 summarizes the distribution of the study subjects by gender and clinical presentations. Out of 82 male patients that presented with nasal congestions, 11/82 (13.4\%), 23 (28\%), and $48(58.5 \%)$ of the patients presented with mild, moderate, and severe nasal congestions, respectively, and the relative risk (RR) (95\% confidence interval, 95\% CI) was 0.98 (0.8311 to 1.1736). Out of 27 female patients that presented with nasal congestions, 6/27 (22.2\%), 7 (26\%), and 14 (51.8\%) of the patients presented with mild, moderate, and severe nasal congestions, respectively, as indicated in Table 3 and Figure 4.

Out of 93 male patients that presented with nasal blockages, 8/93 (8.6\%), $19(20.4 \%)$, and $66(71 \%)$ of the patients presented with mild, moderate, and severe nasal blockages, respectively, and the RR ( $95 \% \mathrm{CI}$ ) was 0.96 (0.2058 to 4.5683 ). Out of 30 female patients that presented with nasal blockages, $7 / 30(23.3 \%), 7(23.3 \%)$, and $16(53.3 \%)$ of the patients presented with mild, moderate, and severe nasal blockages, respectively, as indicated in Table 3 and Figure 4.

Out of 88 male patients that presented with breathing troubles, 11/88 (12.5\%), $22(26 \%)$, and $55(62.5 \%)$ of the patients presented with mild, moderate, and severe breathing troubles, respectively, and the RR (95\% CI) was 1.09 (0.9148 to 1.3116). Out of 26 female patients that presented with breathing troubles, $6 / 26$ (23\%), 5 (19.2\%), and $15(58 \%)$ of the patients presented with mild, moderate, and severe breathing troubles, respectively, as indicated in Table 3 and Figure 4.

Out of 84 male patients that presented with sleeping troubles, 13/84 (15.5\%), $15(18 \%)$, and $56(66.7 \%)$ of the 
TABLE 2: Distribution of the study subjects by clinical presentations.

\begin{tabular}{lccccc}
\hline Variable & No & Mild & Moderate & Severe & Total \\
\hline Nasal congestions & 22 & 17 & 30 & 62 & 131 \\
Nasal blockages & 8 & 15 & 26 & 82 & 131 \\
Breathing troubles & 17 & 17 & 27 & 70 & 70 \\
Sleeping troubles & 21 & 31 & 20 & 34 \\
Exercise problems & 38 & & & 131 \\
\hline
\end{tabular}

TABLE 3: Distribution of the study subjects by gender and clinical presentations.

\begin{tabular}{|c|c|c|c|c|c|c|}
\hline Variable & Category & No & Mild & Moderate & Severe & RR (95\% CI) \\
\hline \multicolumn{7}{|c|}{ Nasal congestions } \\
\hline & Males & 17 & 11 & 23 & 48 & \multirow{2}{*}{$0.98(0.8311$ to 1.1736$)$} \\
\hline & Females & 5 & 6 & 7 & 14 & \\
\hline \multicolumn{7}{|c|}{ Nasal blockages } \\
\hline & Males & 6 & 8 & 19 & 66 & \multirow{2}{*}{$0.96(0.2058$ to 4.5683$)$} \\
\hline & Females & 2 & 7 & 7 & 16 & \\
\hline \multicolumn{7}{|c|}{ Breathing troubles } \\
\hline & Males & 11 & 11 & 22 & 55 & \multirow{2}{*}{$1.09(0.9148$ to 1.3116$)$} \\
\hline & Females & 6 & 6 & 5 & 15 & \\
\hline \multicolumn{7}{|c|}{ Sleeping troubles } \\
\hline & Males & 15 & 13 & 15 & 56 & \multirow{2}{*}{$1.04(0.8670$ to 1.2579$)$} \\
\hline & Females & 6 & 7 & 5 & 14 & \\
\hline \multicolumn{7}{|c|}{ Exercise problems } \\
\hline & Males & 26 & 25 & 20 & 28 & \multirow{2}{*}{$1.17(0.8802$ to 1.5815$)$} \\
\hline & Females & 12 & 6 & 8 & 6 & \\
\hline
\end{tabular}

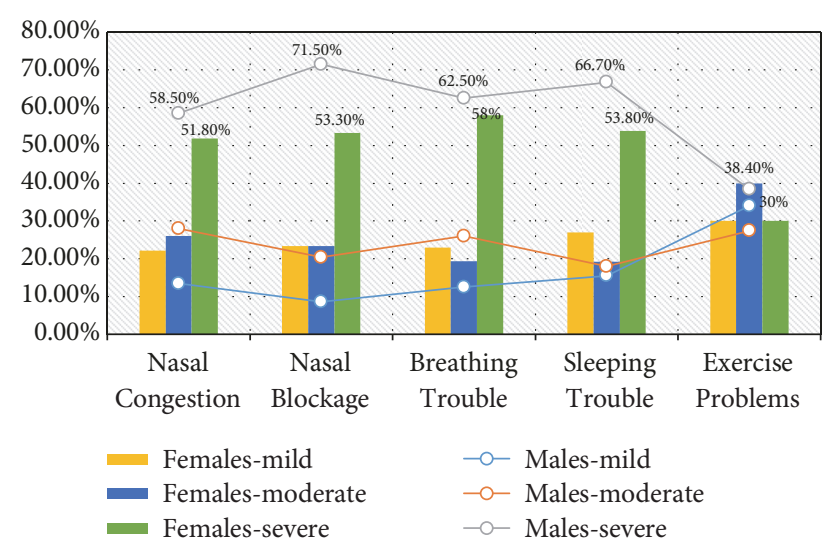

FIGURE 4: Description of patients by initial clinical presentations and gender.

patients presented with mild, moderate, and severe sleeping troubles, respectively, and the RR (95\% CI) was 1.04 (0.8670 to 1.2579). Out of 26 female patients that presented with sleeping trouble, $7 / 26$ (27\%), 5 (19.2\%), and 14 (53.8\%) presented with mild, moderate, and severe sleeping troubles, respectively, as indicated in Table 3 and Figure 4.

Out of 73 male patients that presented with exercise problems, 25/73 (34\%), 20 (27.4\%), and 28 (38.4\%) of the patients presented with mild, moderate, and severe exercise problems, respectively, and the RR (95\% CI) was 1.17 (0.8802 to 1.5815). Out of 20 female patients that presented with sleeping troubles, $6 / 20(30 \%), 8(40 \%)$, and $6(30 \%)$ of the patients presented with mild, moderate, and severe exercise problem, respectively, as indicated in Table 3 and Figure 4.

The distribution of the study subjects by age and clinical presentations is summarized in Table 4. Most of the cases with severe nasal congestions were found among age group 26-30 years followed by age range 21-25 representing 17/62 (27.4\%) and 16/62 (25.8\%), respectively; hence, the cases with moderate degree were found among age group 21-25 years followed by age group $<20$ years constituting 14/30 (46.7\%) and $5 / 30(16.7 \%)$, in this order.

Most of the cases with severe nasal blockages were found among age group 21-25 years followed by age group $<20$ representing 24/62 (38.7\%) and 16/62 (25.8\%), respectively; hence, most of the cases with moderate degree were found among age group $<20$ years followed by age group $21-25$ years constituting $9 / 30(30 \%)$ and $8 / 30(26.7 \%)$, in this order, as indicated in Table 4.

Most of the cases with severe breathing troubles were found among age group 21-25 years followed by age group 26-30 representing 24/62 (38.7\%) and 18/62 (29\%), respectively; hence, most of the cases with moderate degree were found among age group 21-25 years followed by $<20$ years constituting $7 / 30(23.3 \%)$ and $3 / 30(10 \%)$, in this order, as indicated in Table 4.

Most of the cases with severe sleeping troubles were found among age group 21-25 years followed by age group 26-30 representing $19 / 62(30.6 \%)$ and $15 / 62(24.2 \%)$, respectively; 
TABLE 4: Distribution of the study subjects by age and clinical presentations.

\begin{tabular}{|c|c|c|c|c|c|c|}
\hline Variable & Category & No & Mild & Moderate & Severe & Total \\
\hline \multicolumn{7}{|c|}{ Nasal congestions } \\
\hline & $<20$ years & 2 & 8 & 5 & 12 & 27 \\
\hline & $21-25$ & 12 & 1 & 14 & 16 & 43 \\
\hline & $26-30$ & 5 & 3 & 3 & 17 & 28 \\
\hline & $31-35$ & 2 & 3 & 4 & 10 & 19 \\
\hline & $36+$ & 1 & 2 & 4 & 7 & 14 \\
\hline & Total & 22 & 17 & 30 & 62 & 131 \\
\hline \multicolumn{7}{|c|}{ Nasal blockages } \\
\hline & $<20$ years & 2 & 0 & 9 & 16 & 27 \\
\hline & 21-25 & 3 & 8 & 8 & 24 & 43 \\
\hline & $26-30$ & 1 & 3 & 4 & 2 & 28 \\
\hline & $31-35$ & 1 & 2 & 3 & 13 & 19 \\
\hline & $36+$ & 1 & 2 & 2 & 9 & 14 \\
\hline \multicolumn{7}{|c|}{ Breathing troubles } \\
\hline & $<20$ years & 5 & 3 & 6 & 13 & 27 \\
\hline & $21-25$ & 6 & 7 & 6 & 24 & 43 \\
\hline & $26-30$ & 4 & 2 & 4 & 18 & 28 \\
\hline & $31-35$ & 2 & 2 & 6 & 9 & 19 \\
\hline & $36+$ & 0 & 3 & 5 & 6 & 14 \\
\hline \multicolumn{7}{|c|}{ Sleeping troubles } \\
\hline & $<20$ years & 5 & 3 & 4 & 15 & 27 \\
\hline & $21-25$ & 8 & 9 & 7 & 19 & 43 \\
\hline & $26-30$ & 5 & 2 & 6 & 15 & 28 \\
\hline & $31-35$ & 3 & 4 & 3 & 9 & 19 \\
\hline & $36+$ & 0 & 2 & 0 & 12 & 14 \\
\hline \multicolumn{7}{|c|}{ Exercise problems } \\
\hline & $<20$ years & 12 & 6 & 5 & 4 & 27 \\
\hline & $21-25$ & 12 & 6 & 12 & 13 & 43 \\
\hline & $26-30$ & 6 & 9 & 6 & 7 & 28 \\
\hline & $31-35$ & 6 & 4 & 4 & 5 & 19 \\
\hline & $36+$ & 2 & 6 & 1 & 5 & 14 \\
\hline
\end{tabular}

hence, most of the cases with moderate degree were found among age group 21-25 years followed by 26-30 years constituting $7 / 30(23.3 \%)$ and $6 / 30(20 \%)$, in this order, as indicated in Table 4.

Most of the cases with severe exercise problems were found among age group 21-25 years followed by 26-30 representing $13 / 62(21 \%)$ and $7 / 62$ (11.3\%), respectively; hence, most of the cases with moderate degree were found among age group 21-25 years followed by 26-30 years constituting $12 / 30(40 \%)$ and $6 / 30(20 \%)$, in this order, as indicated in Table 4.

The distribution of the study subjects by occupations and clinical presentations is summarized in Table 4 . The majority of patients with severe nasal congestions were found among students followed by others constituting 19/62 (30.6\%) and $16(25.8 \%)$ correspondingly, whereas the majority of cases with moderate condition were identified among students and employees representing $9 / 30$ (30\%) and 8 (26.7\%), respectively.

The majority of patients with severe nasal blockages were found among students followed by others constituting
$29 / 62(46.8 \%)$ and $19(30.6 \%)$ correspondingly, whereas the majority of cases with moderate conditions were identified among students and employees representing 11/30 (36.7\%) and $6(20 \%)$, respectively, as indicated in Table 5.

The majority of patients with severe breathing troubles were found among students followed by others constituting 25/62 (40.3\%) and 17 (27.4\%) correspondingly, whereas the majority of cases with moderate conditions were identified among students and employees representing 10/30 (33.3\%) and $6(20 \%)$, respectively, as indicated in Table 5.

The majority of patients with severe sleeping troubles were found among students followed by employees constituting 25/62 (40.3\%) and 16 (\%) correspondingly, whereas the majority of cases with moderate conditions were identified among students and employees representing $7 / 30(23.3 \%)$ and $5(16.7 \%)$, respectively, as indicated in Table 5 .

The majority of patients with severe exercise problems were found among students followed by employees constituting 25/62 (40.3\%) and $16(25.8 \%)$ correspondingly, whereas the majority of cases with moderate conditions 
TABLE 5: Distribution of the study subjects by occupation and clinical presentation.

\begin{tabular}{|c|c|c|c|c|c|c|}
\hline Variable & Category & No & Mild & Moderate & Severe & Total \\
\hline \multicolumn{7}{|c|}{ Nasal congestions } \\
\hline & Employees & 3 & 2 & 8 & 11 & 24 \\
\hline & Teachers & 1 & 1 & 4 & 12 & 18 \\
\hline & Students & 9 & 8 & 9 & 19 & 45 \\
\hline & Solders & 2 & 2 & 1 & 4 & 9 \\
\hline & Medicals & 0 & 1 & 1 & 0 & 2 \\
\hline & Others & 7 & 3 & 7 & 16 & 33 \\
\hline \multicolumn{7}{|c|}{ Nasal blockages } \\
\hline & Employees & 0 & 2 & 6 & 16 & 24 \\
\hline & Teachers & 0 & 3 & 2 & 13 & 18 \\
\hline & Students & 2 & 3 & 11 & 29 & 45 \\
\hline & Solders & 1 & 1 & 2 & 5 & 9 \\
\hline & Medicals & 0 & 1 & 1 & 0 & 2 \\
\hline & Others & 5 & 5 & 4 & 19 & 33 \\
\hline \multicolumn{7}{|c|}{ Breathing troubles } \\
\hline & Employees & 2 & 3 & 6 & 13 & 24 \\
\hline & Teachers & 1 & 1 & 4 & 12 & 18 \\
\hline & Students & 5 & 5 & 10 & 25 & 45 \\
\hline & Solders & 2 & 2 & 2 & 3 & 9 \\
\hline & Medicals & 1 & 1 & 0 & 0 & 2 \\
\hline & Others & 6 & 5 & 5 & 17 & 33 \\
\hline \multicolumn{7}{|c|}{ Sleeping troubles } \\
\hline & Employees & 2 & 1 & 5 & 16 & 24 \\
\hline & Teachers & 1 & 4 & 2 & 11 & 18 \\
\hline & Students & 8 & 6 & 7 & 25 & 45 \\
\hline & Solders & 1 & 1 & 2 & 5 & 9 \\
\hline & Medicals & 0 & 1 & 1 & 0 & 2 \\
\hline & Others & 9 & 7 & 3 & 14 & 33 \\
\hline \multicolumn{7}{|c|}{ Exercise problems } \\
\hline & Employees & 5 & 6 & 5 & 8 & 24 \\
\hline & Teachers & 5 & 2 & 5 & 5 & 18 \\
\hline & Students & 17 & 9 & 8 & 11 & 45 \\
\hline & Solders & 3 & 4 & 1 & 1 & 9 \\
\hline & Medicals & 1 & 0 & 1 & 0 & 2 \\
\hline & Others & 7 & 10 & 8 & 8 & 33 \\
\hline
\end{tabular}

were identified among students and others representing 8/30 $(26.7 \%)$ and $8(26.7 \%)$, respectively, as indicated in Table 5.

Out of 131 patients, $112(85.5 \%)$ were diagnosed with DNS and the remaining 19 (14.5\%) were found with conditions other than DNS. All of the patients were selected for septoplasty. Out of 99 males, 87 (87.9\%) were found with DNS; hence, out of 32 females, 25 (78\%) were found with DNS.

\section{Discussion}

Nasal obstruction is a common problem, which is caused by several factors with the greatest being DNS. The nasal septum has a vital role in both the look and function of the nose. Deviation of the nose is reciprocal and amendment needs an attentive, anatomically based treatment. Therefore, the present study focused on the association between initial clinical presentation (mainly nasal obstruction) of patients selected for septoplasty and demographical characteristics in Northern Saudi Arabia.

In the present study, out of 131 patients with nasal obstruction, about $76 \%$ were males and only $24 \%$ were females. DNS is a very prevalent condition in several parts of the world, with severe symptoms such as nasal obstruction and rhinitis. Although some studies have showed similar results to our findings that DNS is more prevalent in men $[10,11]$, some epidemiology studies reported that women have nearly double the rate of chronic rhinosinusitis (CRS) when compared with men $[12,13]$, whereas other studies found no difference [11, 14]. Studies from Saudi Arabia have shown that DNS is more common among males than females [15]. 
In the present study, DNS was more common in age range 21 to 29 years. Although diverse studies reported varying percentages with mostly age mean around 30 years old, similar results have been previously reported $[16,17]$.

The great majority of the cases in this series were reported in the year 2016 followed by year 2014. Although in our extensive search regarding the epidemiology of DNS we did not come across a study that compares the prevalence of DNA in different years, singly scattered reports from Saudi Arabia were relatively comparable to our findings $[17,18]$. Annual septoplasty rates, however, differ between countries. More than 20,000 septoplasties, i.e., 3.8 septoplasties per 10,000 inhabitants, were performed in England between 2012 and 2013[8]. In the Netherlands, 10,000 septoplasties, i.e., 6.0 septoplasties per 10,000 inhabitants, were performed as a single procedure or in combination with turbinate surgery in 2010 [19].

With regard to occupations, most of the patients were students followed by employees. However, not all of our study population were cases of DNS; some were cases of nasal obstruction due to other etiological factors. Reversible nasal congestion is usually caused by mucosal inflammation and secretions. In contrast, fixed or relatively constant congestion (i.e., obstruction) may be due to occlusion (e.g., nasal polyps, foreign body), anatomical variation (e.g., septal deformity, turbinate hypertrophy), or, rarely, neoplasm. In some cases, abnormal sensory perception may also contribute to a patient's perception of nasal congestion. A differential diagnosis of reversible nasal congestion includes allergic rhinitis, nonallergic rhinitis, vasomotor rhinitis, exaggerated nasal cycle, acute viral rhinitis, acute viral rhinosinusitis, acute bacterial rhinitis, acute bacterial rhinosinusitis, chronic inflammatory or infectious rhinosinusitis, rhinitis medicamentosa, sarcoidosis, Wegener's granulomatosis, Churg-Strauss syndrome, and rhinoscleroma [20].

In the present study, approximately $85.5 \%$ of the patients presented with DNS. Similar findings were previously reported in diverse studies. In a study that investigated the correlation of nasal septal deviations and chronic rhinosinusitis, DNS was found in 49 (81.7\%) subjects; 11 (18.3\%) had it in both right and left sides, $16(26.7 \%)$ in the right side alone, and $22(36.7 \%)$ in the left side. The commonest types of septal deviations in the left side were posteroinferior $(10,16.66 \%)$ and anteroinferior $(7,11.7 \%)$. In the right side, the corresponding numbers were $9(15 \%)$ and 7 (11.7\%) [21]. Some studies have reported nasal septal deviation in $20-31 \%$ of the community and also revealed that severe deviation predisposed the individuals to rhinosinusitis [22, 23].

Nasal septoplasty is one of the most common procedures in otolaryngology owing to the high prevalence of nasal obstruction from septal deviation [24]. As stressed in the literature, identification of the C- and S-shaped deformities at the time of planning remains crucial for identifying potentially complex surgeries compared to less technically challenging operative interventions such as septal tilts $[25,26]$.

Conclusion. Nasal obstruction is prevalent in Northern Saudi Arabia with peaks being in the years 2016 and 2014 with the most etiological factor being DNS. DNS is commonly seen among men in Northern Saudi Arabia and most patients underwent septoplasty in their twenties. Septoplasty has a good prospect to be accepted as a quick practice, with patient effective perioperative care being the basis of good outcomes.

\section{Conflicts of Interest}

The authors declare that they have no conflicts of interest.

\section{References}

[1] S. Umihanic, F. Brkic, M. Osmic et al., "The discrepancy between subjective and objective findings after septoplasty," Medical Archives, vol. 70, no. 5, pp. 336-338, 2016.

[2] Y. Haroon, H. A. Saleh, and A. H. Abou-Issa, "Nasal soft tissue obstruction improvement after septoplasty without turbinectomy," European Archives of Oto-Rhino-Laryngology, vol. 270, no. 10, pp. 2649-2655, 2013.

[3] O. Kuduban, F. Bingol, A. Budak, and C. Kucur, "The reason of dissatisfaction of patient after septoplasty," Eurasian Journal of Medicine, vol. 47, no. 3, pp. 190-193, 2015.

[4] S. D. Reitzen, W. Chung, and A. R. Shah, "Nasal septal deviation in the pediatric and adult populations," Ear, Nose \& Throat Journal, vol. 90, no. 3, pp. 112-115, 2011.

[5] P. D. Manoukian, J. R. Wyatt, D. A. Leopold, and E. B. Bass, "Recent trends in utilization of procedures in otolaryngologyhead and neck surgery," The Laryngoscope, vol. 107, no. 4, pp. 472-477, 1997.

[6] I. Baumann, "Septoplasty update," Laryngorhinootologie, vol. 89, no. 6, pp. 373-384, 2010.

[7] A. Alotaibi and B. A. Almutlaq, "Post-surgical Outcomes of Patients Undertaken Septoplasty with Regard to Initial Clinical Complains," Research in Otolaryngology, vol. 6, no. 6, pp. 73-80, 2017.

[8] Hospital Episode Statistics, Admitted Patient Care, England 2012-13: Procedures and interventions [Internet]. Leeds, England: Health \& Social Care Information Centre, 2013. Accessed 11 July 2014.

[9] J. D. Bloom, S. E. Kaplan, B. S. Bleier, and S. A. Goldstein, "Septoplasty Complications: Avoidance and Management," Otolaryngologic Clinics of North America, vol. 42, no. 3, pp. 463-481, 2009.

[10] V. Sriprakash, "Prevalence and clinical features of nasal septum deviation: a study in an urban centre," International Journal of Otorhinolaryngology and Head and Neck Surgery, vol. 3, no. 4, pp. 842-844, 2017.

[11] Y. Min, H. Jung, H. Kim, S. Park, and K. Yoo, "Prevalence and risk factors of chronic sinusitis in Korea: results of a nationwide survey," European Archives of Oto-Rhino-Laryngology, vol. 253, no. 7, pp. 435-439, 1996.

[12] J. S. Schiller, J. W. Lucas, B. W. Ward, and J. A. Peregoy, "Summary health statistics for U.S. adults: National Health Interview Survey, 2010," Vital Health Stat, vol. 10, no. 252, pp. 1-207, 2012.

[13] Y. Chen, R. Dales, and M. Lin, "The epidemiology of chronic rhinosinusitis in Canadians," The Laryngoscope, vol. 113, no. 7, pp. 1199-1205, 2003.

[14] D. Hastan, W. J. Fokkens, C. Bachert et al., "Chronic rhinosinusitis in Europe-an underestimated disease. A GA ${ }^{2}$ LEN study," Allergy: European Journal of Allergy and Clinical Immunology, vol. 66, no. 9, pp. 1216-1223, 2011. 
[15] S. Alharethy, T. Aldrees, R. Aljrid, A. Alanazi, S. K. Algaryan, and Y. J. Jang, "Common nasal deformities among rhinoplasty patients in a university hospital in Saudi Arabia," Annals of Saudi Medicine, vol. 37, no. 3, pp. 207-211, 2017.

[16] D. Etigadda and D. Majeed, "Clinical and Radiological Evaluation of Deviated Nasal Septum in Classifying and Surgical Management of the Deviated Septums," IOSR Journal of Dental and Medical Sciences, vol. 16, no. 2, pp. 13-20, 2017.

[17] A. M. Al-Shehri, H. M. Amin, and A. Necklawy, "Retrospective study of endoscopic nasal septoplasty," Biomedical Research (India), vol. 24, no. 3, pp. 337-340, 2013.

[18] R. A. Alrumaih, M. M. Ashoor, A. A. Obidan, K. M. AlKhater, and S. A. Al-Jubran, "Radiological sinonasal anatomy: exploring the saudi population," Saudi Medical Journal, vol. 37, no. 5, pp. 521-526, 2016.

[19] Dutch Hospital Data, Utrecht, the Netherlands: DHD, 2010, http://ghdx.healthdata.org/organizations/dutch-hospital-datadhd.

[20] M. Stewart, B. J. Ferguson, and L. Fromer, "Epidemiology and burden of nasal congestion," Journal of General Internal Medicine, vol. 3, pp. 37-45, 2010.

[21] S. A. Madani, S. A. Hashemi, and M. Modanluo, "The incidence of nasal septal deviation and its relation with chronic rhinosinusitis in patients undergoing functional endoscopic sinus surgery," Journal of the Pakistan Medical Association, vol. 65, no. 6, pp. 612-614, 2015.

[22] R. A. Lebowitz, E. Brunner, and J. B. Jacobs, "The agger nasi cell: radiological evaluation and endoscopic management in chronic frontal sinusitis," Operative Techniques in Otolaryngology-Head and Neck Surgery, vol. 6, no. 3, pp. 171175, 1995.

[23] H. H. Wanamaker, "Role of Haller's cell in headache and sinus disease: a case report," Otolaryngology-Head and Neck Surgery, vol. 114, no. 2, pp. 324-327, 1996.

[24] S. P. Most and S. F. Rudy, "Septoplasty: basic and advanced techniques," Facial Plastic Surgery Clinics of North America, vol. 25, no. 2, pp. 161-169, 2017.

[25] I. Baumann and H. Baumann, "A new classification of septal deviations," Rhinology, vol. 45, no. 3, pp. 220-223, 2007.

[26] J. W. Lee and S. R. Baker, "Correction of caudal septal deviation and deformity using nasal septal bone grafts," JAMA Facial Plastic Surgery, vol. 15, no. 2, pp. 96-100, 2013. 


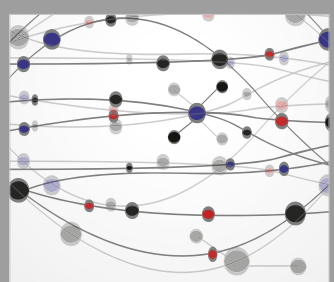

The Scientific World Journal
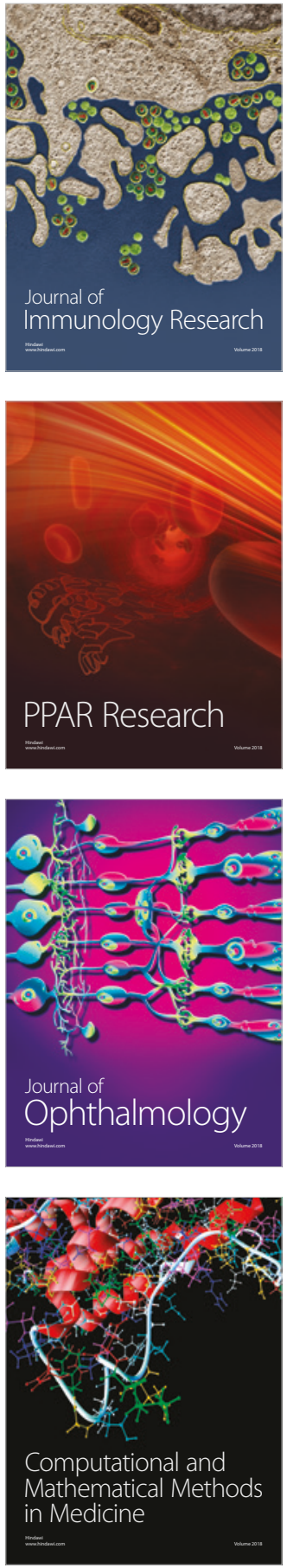

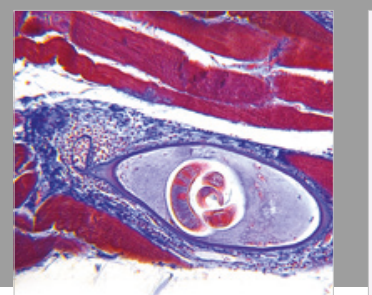

Gastroenterology Research and Practice

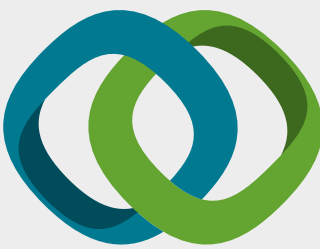

\section{Hindawi}

Submit your manuscripts at

www.hindawi.com
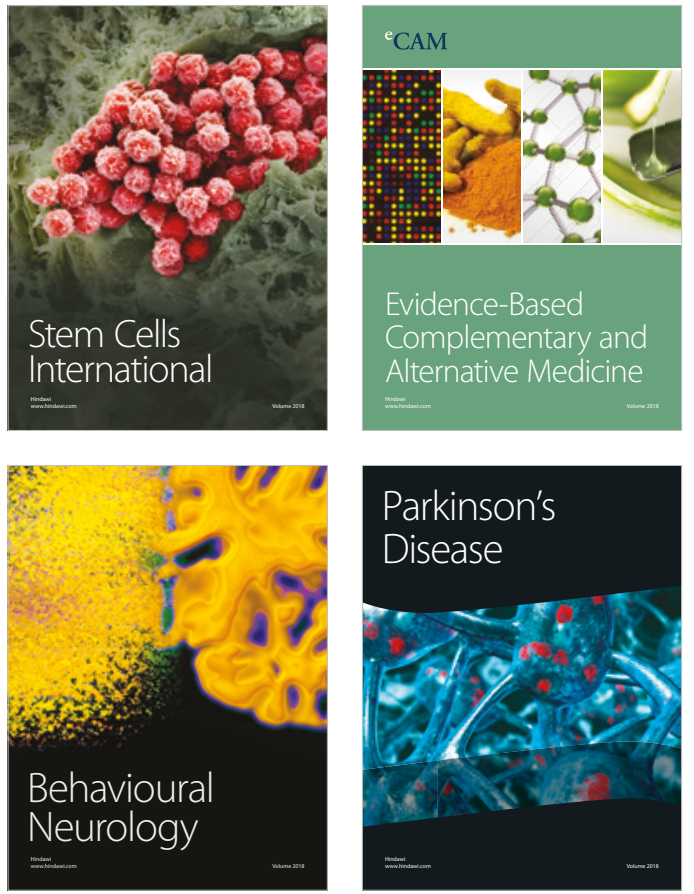

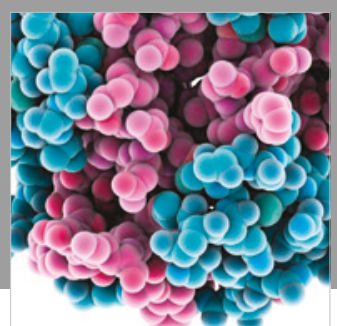

ournal of

Diabetes Research

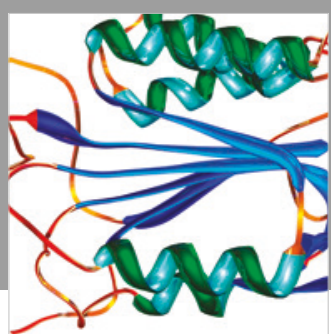

Disease Markers
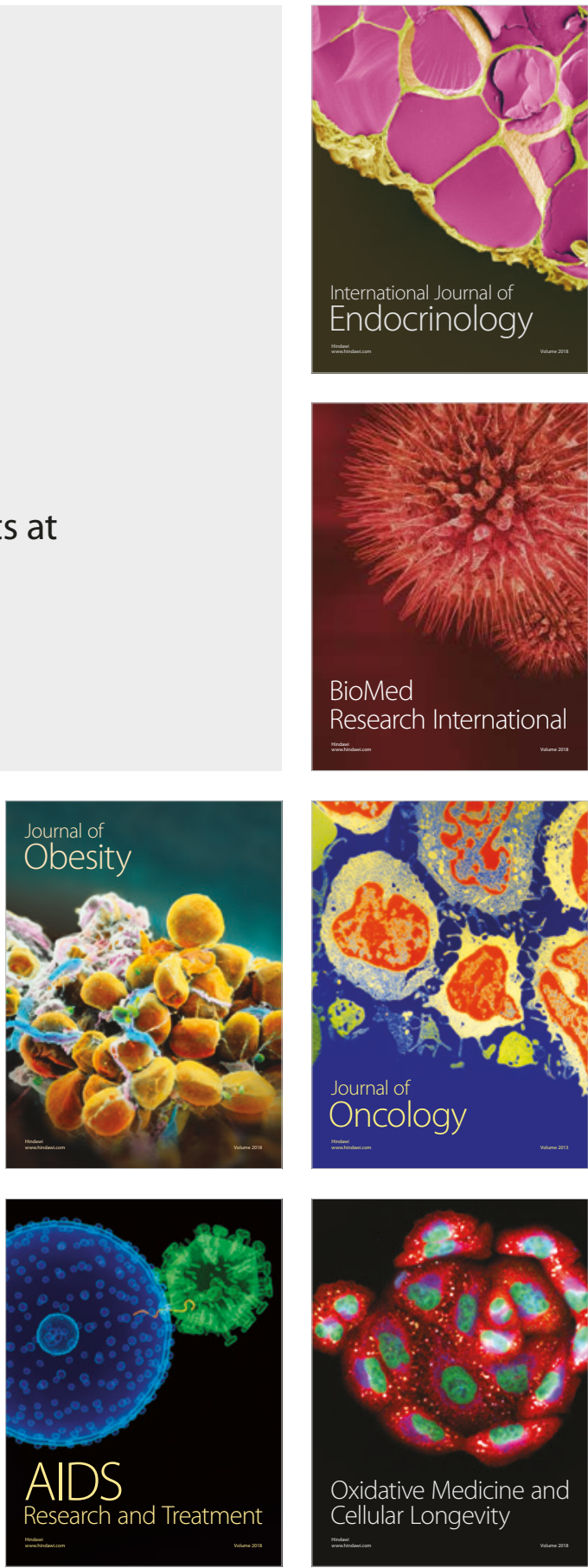